\title{
PENGEMBANGAN GAME SIMULASI PENANAMAN PADI SITU BAGENDIT (STUDI KASUS PADA UPTD PERTANIAN KECAMATAN NGANTANG)
}

\author{
Nisa Rahma Della ${ }^{1}$, Indra Dharma Wijaya ${ }^{2}$, Budi Harijanto ${ }^{3}$ \\ Program Studi Teknik Informatika, Jurusan Teknologi Informasi, Politeknik Negeri Malang \\ 1nisarahma@gmail.com, ${ }^{2}$ indra.dharma@gmail.com, ${ }^{3}$ budi.hijet@gmail.com
}

\begin{abstract}
Abstrak
Pertanian merupakan sektor utama yang menyumbang hamper setengah perekonomian di Indonesia. Pertanian di Indonesia dalam pembangunannya memiliki berbagai masalah yang dapat memperlambat laju perkembangan pertanian di Indonesia. Masalah muncul dari berbagai faktor diantaranya minimnya pendidikan petani, kemudian mahalnya kebutuhan biaya pertanian, lingkungan untuk mengembangkan pertanian padi mahal dan rendahnya minat generasi muda untuk mempelajari dan menekuni bidang pertanian. Oleh karena itu perlu adanya media pembelajaran tentang pertanian yang dispesifikasikan pada tanaman padi yang tidak perlu mengeluarkan biaya yang mahal dengan memanfaatkan teknologi multimedia berupa game. Game yang dibuat bergenre game simulasi yang mensimulasikan penanaman padi. Game dirancang dan dimplementasikan menggunakan algoritma fuzzy untuk menentukan tingkat kemampuan pemain. Game yang dibuat juga telah diuji coba kepada user dengan tingkat kepuasan pengetahuan yang didapat oleh pengguna sebesar $84 \%$.
\end{abstract}

Kata Kunci : pertanian, simulasi, game, algoritma fuzzy

\section{Pendahuluan}

Negara Indonesia adalah negara yang kaya sumber daya alamnya. Sebagian besar masyarakat Indonesia bermata pencaharian sebagai petani. Oleh karena itu Indonesia terkenal sebagai negara agraris.

Pertanian merupakan sektor primer dalam perekonomian Indonesia. Artinya pertanian merupakan sektor utama yang menyumbang hampir dari setengah perekonomian. Pertanian juga memiliki peran nyata sebagai penghasil devisa negara melalui ekspor.

Dengan adanya usaha pembangunan pertanian, muncul pula masalah-masalah yang akan memperlambat laju perkembangan pertanian di Indonesia. Masalah itu muncul dari berbagai faktor diantaranya minimnya pendidikan petani kemudian kebutuhan biaya, pengetahuan dan lingkungan untuk mengembangkan pertanian padi sendiri tidaklah murah, serta rendahnya minat generasi muda untuk mempelajari dan menekuni bidang pertanian

Berawal dari permasalahan tersebut muncul salah satu pemanfaatan teknologi multimedia yang sedang berkembang pesat dengan berbagai macam jenis genre yaitu game. Mulai dari anak-anak hingga dewasa sangat menyukai game sesuai dengan genre yang mereka sukai. Salah satu jenis game yang digemari adalah game bergenre life simulation, dimana jenis game ini berusaha untuk mensimulasikan kehidupan secara nyata dan detail. Game yang akan dibuat adalah pembuatan game simulasi penanaman padi. Game ini akan dibuat menyerupai dengan keaslian dalam dunia nyata. Permainan bertipe simulasi dengan tema pertanian yang sudah ada seperti Farm Frenzy, Farmville serta Harvest Moon memiliki user yang antusias. Namun game tersebut tidak menspesifikasikan pada tanaman tertentu. Sehingga game simulasi pertanian yang akan dibuat akan berfokus pada tanaman padi Situ Bagendit dengan tujuan memberikan pengetahuan tentang cara menanam padi yang baik dan menghasilkan panen yang maksimal.

\section{Landasan Teori}

\subsection{Padi dan Alur Penanaman Padi}

Tumbuhan padi (Oryza sativa L) termasuk golongan tumbuhan Gramineae, yang mana ditandai dengan batang yang tersusun dari beberapa ruas. Tumbuhan padi bersifat merumpun, artinya tanaman tanamannya anak beranak. Bibit yang hanya sebatang saja ditanamkan dalam waktu yang sangat dekat, dimana terdapat 20-30 atau lebih anakan atau tunas tunas baru (Siregar, 1981).

Dalam proses pertanian padi ada beberapa tahapan, tahapan tersebut pada dasarnya adalah sebagai berikut :
a. Pembibitan
b. Pengolahan lahan
c. Penanaman 
d. Pemeliharaan

e. Panen

\subsection{Game}

Game merupakan kata dalam bahasa inggris yang berarti permainan. Permainan adalah sesuatu yang dapat dimainkan dengan aturan tertentu sehingga ada yang menang dan ada yang kalah, biasanya dalam konteks tidak serius atau dengan tujuan refreshing.

Teori permainan pertama kali ditemukan oleh sekelompok ahli Matematika pada tahun 1944. Teori itu dikemukakan oleh John von Neumann and Oskar Morgenstern yang berisi: "Permainan terdiri atas sekumpulan peraturan yang membangun situasi bersaing dari dua sampai beberapa orang atau kelompok dengan memilih strategi yang dibangun untuk memaksimalkan kemenangan lawan. Peraturan-peraturan menentukan kemungkinan tindakan untuk setiap pemain, sejumlah keterangan diterima setiap pemain sebagai kemajuan bermain, dan sejumlah kemenangan atau kekalahan dalam berbagai situasi".

\subsection{Game Simulasi}

Game jenis ini seringkali menggambarkan dunia di dalam game sedekat mungkin dengan dunia nyata dan memperhatikan dengan detil berbagai faktor. Dari mencari jodoh dan pekerjaan, membangun rumah, gedung hingga kota, mengatur pajak dan dana kota hingga keputusan memecat atau menambah karyawan. Dunia kehidupan rumah tangga sampai bisnis membangun konglomerasi, dari jualan limun pinggir jalan hingga membangun laboratorium cloning. Game jenis ini membuat pemain harus berpikir untuk mendirikan, membangun dan mengatasi masalah dengan menggunakan dana yang terbatas. Contoh dari game simulasi adalah Sim City, The Sims, Farm Frenzy, Harvest Moon ,Farmville, Tamagotchi dan lain sebagainya.

\subsection{Kecerdasan Buatan}

Kecerdasan buatan (Artificial Intelligence) didefinisikan sebagai kecerdasan yang ditunjukkan oleh suatu entitas buatan. Kecerdasan diciptakan dan dimasukkan ke dalam suatu mesin (komputer) agar dapat melakukan pekerjaan seperti yang dapat dilakukan manusia. Beberapa macam bidang yang menggunakan kecerdasan buatan salah satunya adalah game.

Perkembangan game saat ini tidak lepas dari kecerdasan buatan (Artificial Intelligence). Berdasarkan perkembangan game yang pesat pada saat ini , maka tidak dipungkiri bahwa dibutuhkan sesuatu yang berbeda pada rule permainannya. Hal ini sangat berkaitan dengan kecerdasan buatan (Artificial Intelligence) yang diterapkan pada game. Sebelumnya, sebuah game, jika sudah dimainkan sampai tuntas oleh player, maka ketika player yang sama memulai lagi permainan dari awal, maka rule permainannya akan sama. Namun untuk saat ini sesuai dengan perkembangan game dan kecerdasan buatan yang diterapkan, sistem dalam game sudah dapat belajar mengenali pola permainan dari player dan ketika player tersebut memulai permainan kembali, maka system ini akan menggunakan rule yang berbeda, sehingga game menjadi lebih menarik dan menantang untuk dimainkan.

\subsection{Non Player Character (NPC)}

Autonomous character adalah jenis otonomous agent yang ditujukan untuk penggunaan komputer animasi dan media interaktif seperti games dan virtual reality (Reynold, 1999). Agen ini mewakili tokoh dalam cerita atau permainan dan memiliki kemampuan untuk improvisasi tindakan mereka. Ini adalah kebalikan dari seorang tokoh dalam sebuah film animasi, yang tindakannya ditulis di muka, dan untuk "avatar" dalam sebuah permainan atau virtual reality, tindakan yang diarahkan secara real time oleh pemain. Dalam permainan, karakter otonom biasanya disebut Non Player Character (NPC).

Perilaku karakter yang otonom dapat lebih baik dipahami dengan membaginya menjadi beberapa lapisan. Lapisan ini dimaksudkan hanya untuk kejelasan dan kekhususan dalam diskusi yang akan mengikuti. Gambar 1 menunjukkan sebuah divisi gerak perilaku otonom hirarki karakter menjadi tiga lapisan: seleksi tindakan, steering, dan penggerak.

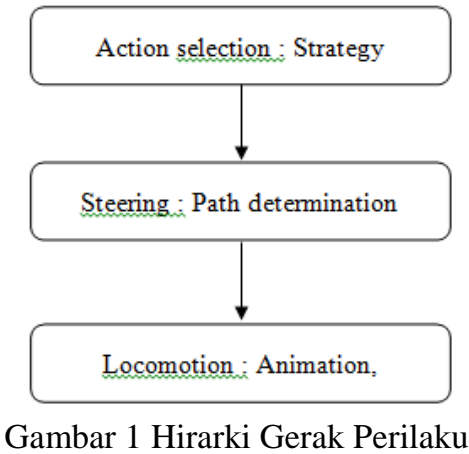

\subsection{Fuzzy Logic}

Logika fuzzy adalah cabang dari sistem kecerdasan buatan (Artificial Intelegent) yang meniru kemampuan manusia dalam berfikir ke dalam bentuk algoritma yang kemudian dijalankan oleh mesin. Algoritma ini digunakan dalam berbagai aplikasi pemrosesan data yang tidak dapat direpresentasikan dalam bentuk biner. Logika fuzzy menginterpretasikan statemen yang samar menjadi sebuah pengertian yang logis.

- Himpunan Fuzzy

Himpunan fuzzy merupakan suatu pengembangan lebih lanjut tentang konsep 
himpunan dalam matematika. Himpunan Fuzzy adalah rentang nilai-nilai. Masing-masing nilai mempunyai derajat keanggotaan (membership) antara 0 sampai dengan 1. Ungkapan logika Boolean menggambarkan nilai-nilai "benar" atau "salah". Logika fuzzy menggunakan ungkapan misalnya : "sangat lambat","agak sedang", "sangat cepat" dan lain-lain untuk mengungkapkan derajat intensitasnya (Kusumadewi dan Purnomo, 2010).

\section{- $\quad$ Fuzzifikasi}

Proses fuzzifikasi merupakan proses untuk mengubah variabel non fuzzy (variabel numerik) menjadi variabel fuzzy (variabel linguistik). Nilai masukan-masukan yang masih dalam bentuk variabel numerik yang telah dikuantisasi sebelum diolah oleh pengendali fuzzy harus diubah terlebih dahulu ke dalam variabel fuzzy. Melalui fungsi keanggotaan yang telah disusun maka nilai-nilai masukan tersebut menjadi informasi fuzzy yang berguna nantinya untuk proses pengolahan secara fuzzy pula. Proses ini disebut fuzzifikasi (Kusumadewi dan Purnomo, 2010).

- Inferencing (Rule Base)

Pada umumnya, aturan-aturan fuzzy dinyatakan dalam bentuk "IF...THEN" yang merupakan inti dari relasi fuzzy. Relasi fuzzy, dinyatakan dengan $R$, juga disebut implikasi fuzzy (Kusumadewi dan Purnomo, 2010). Untuk mendapatkan aturan "IF ...THEN" ada dua cara utama:

1. Menanyakan ke operator manusia yang dengan cara manual telah mampu mengendalikan sistem tersebut, dikenal dengan "human expert".

2. Dengan menggunakan algoritma pelatihan berdasarkan data-data masukan dan keluaran.

- Defuzzifikasi

Keputusan yang dihasilkan dari proses penalaran masih dalam bentuk fuzzy, yaitu berupa derajat keanggotaan keluaran. Hasil ini harus diubah kembali menjadi variabel numerik non fuzzy melalui proses defuzzifikasi (Kusumadewi dan Purnomo, 2010).

\subsection{Unity}

Unity Engine dapat mengolah beberapa data seperti objek tiga dimensi, suara, teksture, dan lain sebagainya. Keunggulan dari unity engine ini dapat bekerja pada grafik dua dimensi dan tiga dimensi. Namun engine ini lebih konsentrasi pada pembuatan grafik tiga dimensi. Dari beberapa game engine yang sama-sama bekerja pada grafik tiga dimensi, unity engine dapat bekerja lebih banyak.

\subsection{Media Pembelajaran}

Kata media berasal dari bahasa latin medius yang secara harfiah berarti 'tengah', 'perantara' atau 'pengantar'. Dalam bahasa Arab, media adalah perantara atau pengantar pesan dari pengirim kepada penerima pesan. Gerlach \& Ely (1971) mengatakan bahwa media apabila dipahami secara garis besar adalah manusia, materi, atau kejadian yang membangun kondisi yang membuat siswa mampu memperoleh pengetahuan, keterampilan, atau sikap. Secara lebih khusus, pengertian media dalam proses belajar mengajar cenderung diartikan alat-alat grafis, fotografis, atau elektronis untuk menangkap, memproses, dan menyusun kembali informasi visual dan verbal.

Media adalah alat bantu apa saja yang dapat dijadikan sebagai penyalur pesan guna mencapai tujuan pengajaran (Djamarah, 2002: 137). Sedangkan pembelajaran adalah proses, cara, perbuatan yang menjadikan orang atau makhluk hidup belajar (Kamus Besar Bahasa Indonesia, 2002: 17). Jadi, media pembelajaran adalah media yang digunakan pada proses pembelajaran sebagai penyalur pesan antara guru dan siswa agar tujuan pengajaran tercapai.

\section{Metodologi Penelitian}

Metode yang digunakan dalam penelitian ini menggunakan metode Penelitian dan Pengembangan (Research and Development). Metode Penelitian dan Pengembangan adalah metode yang digunakan untuk menghasilkan suatu produk perangkat lunak dan menguji kelayakan perangkat lunak yang dibangun. Menurut Sugiyono (2010), metode Penelitian dan Pengembangan adalah metode yang digunakan untuk menghasilkan produk tertentu dan menguji keefektifan produk terebut.

\subsection{Metode Pengolah Data}

Dalam mengolah data ini dibutuhkan sebuah variabel yang digunakan sebagai input. Variabel yang digunakan jumlah kecepatan dan ketepatan. Variabel yang digunakan setiap tingkatan akan selalu berubah. Berikut dijelaskan tentang integrasi fuzzy dengan game menanam padi sehingga menghasilkan nilai mahir, sedang dan rendah.

\subsection{Metode Pengembangan Perangkat Lunak}

Pengembangan game simulasi dilakukan dengan mengaplikasikan metodologi Multimedia Development Life Cycle (MDLC). Pengembangan multimedia harus melalui tahapan-tahapan yang terancang dengan baik dan runtut agar produk yang dihasilkan memiliki kualitas yang baik dan tepat digunakan dalam pembelajaran. Tahapan pengembangan dalam Multimedia Development Life Cycle $(M D L C)$ ini terdiri dari 6 tahap yaitu:

1. Perencanaan

Tahapan pada proses ini meliputi pembuatan konsep mengenai game yang akan dibuat. 
2. Perancangan

Pada fase design (perancangan) dimulai dengan membuat garis besar dari tampilan dan informasi yang akan ditampilkan di layar. Tahap ini biasanya menggunakan storyboard untuk menggambarkan deskripsi tiap scene, dengan mencantumkan semua objek multimedia dan tautan ke scene lain. Perancangan fuzzy logic mamdani pada game simulasi ini seperti yang dibawah ini:

Fuzzy Logic di dalam game akan digunakan untuk menentukan macam-macam kemampuan bermain bertani dari pemain. Fuzzy Logic yang digunakan adalah metode Mamdani. Analisa fuzzy logic tahap-tahapnya adalah sebagai berikut.

\section{a. Pembentukan Himpunan Fuzzy Logic}

Dalam game ini digunakan 3 variabel dalam fungsi fuzzy, variabel tersebut yaitu :

1. Variabel Kecepatan sebagai variabel input.

2. Variabel Ketepatan sebagai variabel input.

3. Variabel Kemampuan sebagai variabel output.

\section{b. Komposisi Aturan}

1. Fungsi Keanggotaan Kecepatan (A)

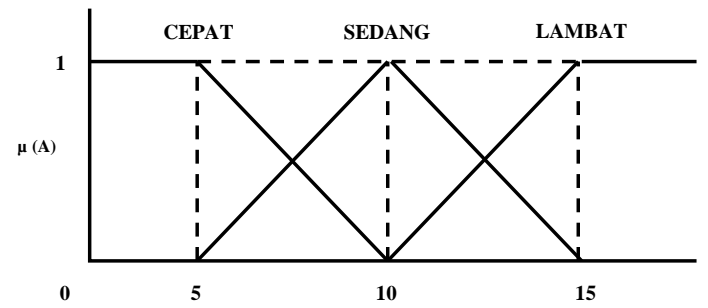

Gambar 2 Parameter Kecepatan (A)

$\mu$ cepat $(\mathrm{A})=\left\{\begin{array}{l}0 \quad ; \mathrm{A} \leq 0 \text { atau } \mathrm{A} \geq 10 \\ (1) ; 0 \leq \mathrm{A} \leq 5 \\ \left(\frac{10-A}{5}\right) ; 5 \leq \mathrm{A} \leq 10\end{array}\right.$

$\mu$ sedang $(\mathrm{A})=\left\{\begin{array}{l}0 ; \mathrm{A} \leq 5 \text { atau } \mathrm{A} \geq 15 \\ \left(\frac{A-5}{5}\right) ; 5 \leq \mathrm{A} \leq 10 \\ \left(\frac{15-A}{5}\right) ; 10 \leq \mathrm{A} \leq 15\end{array}\right.$

$\mu$ banyak $(\mathrm{A})=\left\{\begin{array}{cc}0 ; & \mathrm{A} \leq 10 \\ \left(\frac{A-10}{5}\right) ; & 10 \leq \mathrm{A} \leq 15 \\ 1 ; & \mathrm{A} \geq 15\end{array}\right.$

2. Fungsi Keanggotaan Ketepatan $(H)$

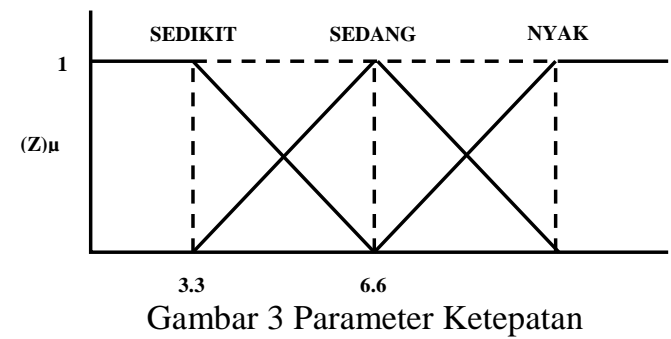

$\mu \quad$ sedikit $(\mathrm{H})=\left\{\begin{array}{c}0 \quad ; \mathrm{H} \leq 0 \text { atau } \mathrm{H} \geq 66,6 \\ (1) ; 0 \leq \mathrm{H} \leq 33,3 \\ \left(\frac{66,6-H}{33,3}\right) ; 33,3 \leq \mathrm{H} \leq 66,6\end{array}\right.$

$\mu$ sedang $(H)=\left\{\begin{array}{l}0 ; H \leq 33,3 \text { atau } H \geq 100 \\ \left(\frac{H-33,3}{33,3}\right) ; 33,3 \leq H \leq 66,6 \\ \left(\frac{100-H}{33,3}\right) ; 66,6 \leq H \leq 100\end{array}\right.$ $\mu \operatorname{banyak}(\mathrm{H})$

$\left\{\begin{array}{cc}0 ; & H \leq 66,6 \\ \left(\frac{H-66,6}{33,3}\right) ; & 66,6 \leq H \leq 100 \\ 1 ; & H \geq 100\end{array}\right.$

3. Fungsi keanggotaan Kemampuan

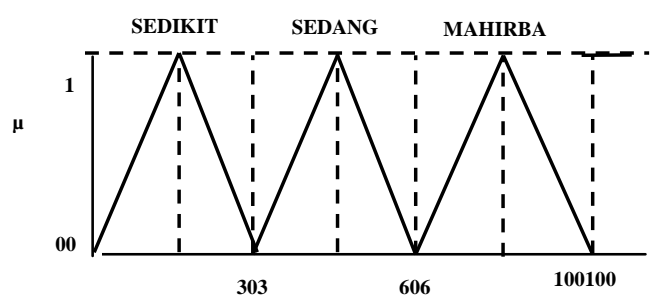

Gambar 4 Diagram Fuzzy Output (Z)

$\mu$ sedikit $=\left\{\begin{array}{c}0 ; \mathrm{Z} \leq 0 \text { atau } \mathrm{Z} \geq 30 \\ \left(\frac{Z}{15}\right) ; 0 \leq \mathrm{Z} \leq 15 \\ \left(\frac{30-Z}{15}\right) ; 15 \leq \mathrm{Z} \leq 30\end{array}\right.$

$\mu$ sedang $(Z)=\left\{\begin{array}{c}0 \quad ; Z \leq 33,3 \text { atau } Z \geq 100 \\ \left(\frac{Z-30}{15}\right) ; 30 \leq Z \leq 45 \\ \left(\frac{60-Z}{15}\right) ; 45 \leq Z \leq 60\end{array}\right.$

$\left\{\begin{array}{c}0 \quad \text { mahir } \\ \quad\left(\frac{Z-60}{20}\right) ; \quad 60 \leq \mathrm{Z} \leq 60 \text { atau } \mathrm{Z} \leq 100 \\ \left(\frac{100-Z}{20}\right) ; 80 \leq \mathrm{Z} \leq 100\end{array}\right.$

Tabel 1 Komposisi aturan

\begin{tabular}{|l|l|l|l|}
\hline IF & $\begin{array}{l}\text { KECEPATA } \\
(\mathrm{A})\end{array}$ & $\begin{array}{l}\text { KETEPATA } \\
(\mathrm{H})\end{array}$ & $\begin{array}{l}\text { Fuzzy } \\
\text { output }(\mathrm{H})\end{array}$ \\
\hline R1 & CEPAT & SEDIKIT & SEDANG \\
\hline R2 & CEPAT & SEDANG & SEDANG \\
\hline R3 & CEPAT & BANYAK & MAHIR \\
\hline R4 & SEDANG & SEDIKIT & RENDAH \\
\hline R5 & SEDANG & SEDANG & SEDANG \\
\hline R6 & SEDANG & BANYAK & SEDANG \\
\hline R7 & LAMBAT & SEDIKIT & RENDAH \\
\hline R8 & LAMBAT & SEDANG & RENDAH \\
\hline R9 & LAMBAT & BANYAK & SEDANG \\
\hline
\end{tabular}




\section{Material Collecting}

Material Collecting (pengumpulan bahan) adalah tahap pengumpulan bahan yang sesuai dengan kebutuhan yang dikerjakan. Bahan-bahan yang dibutuhkan adalah sebagai berikut:

- Gambar : gambar digunakan sebagai objek player, non-player dan lingkungan game.

- Audio : file audio digunakan sebagai musik latar game.

- Software : kebutuhan perangkat lunak yang dibutuhkan untuk menunjang keperluan pembuatan game seperti game engine, editor gambar, dan sebagainya.

\section{Assembly}

Tahap assembly (pembuatan) adalah tahap pembuatan semua objek atau bahan multimedia. Pembuatan aplikasi berdasarkan storyboard yang berasal pada tahap design. Proses ini dimulai dengan pemodelan lingkungan game, pembuatan menu utama game serta penulisan source code.

Pembuatan game Oryza Farm Village dimulai dengan pembuatan desain tanah sawah dengan Unity 5.3.4.

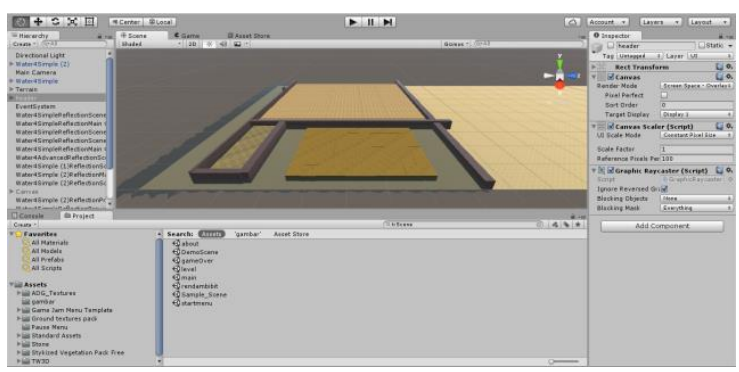

Gambar 5 Pembuatan Desain Sawah

Sawah berfungsi sebagai tempat merendam benih, menyemai benih, menanam padi dan memanen padi. Dalam menanam padi nantinya muncul hama secara random.

5. Testing

Tahap testing (pengujian) dilakukan setelah menyelesaikan tahap pembuatan (assembly) dengan menjalankan aplikasi / program dan dilihat apakah ada kesalahan atau tidak. Pengujian melibatkan pengguna akhir yaitu mahasiswa maupun masyarakat umum. Pada saat pengujian juga diberi kuesioner untuk melihat apakah game tersebut dapat memberikan pembelajaran tentang penanaman padi.

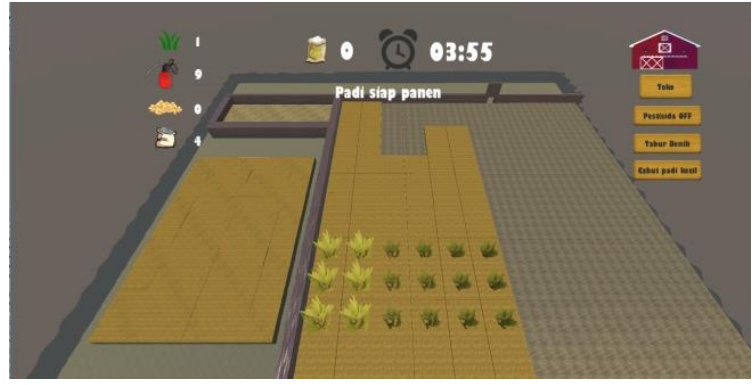

Gambar 6 Scene Main Game Tanaman Padi Siap Panen

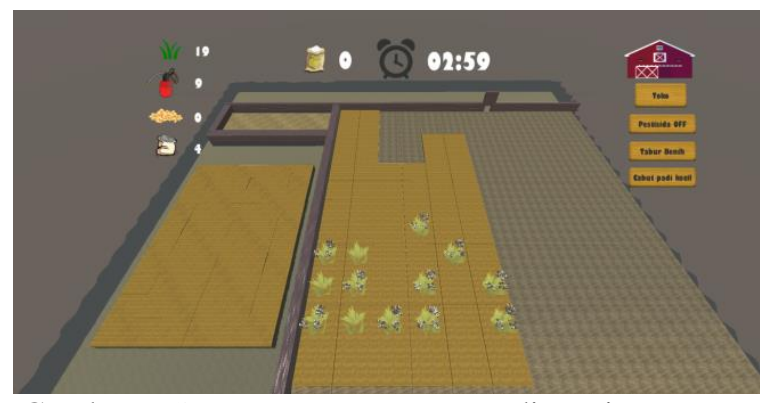

Gambar 7 Scene Main Tanaman Padi Mati Karena Hama

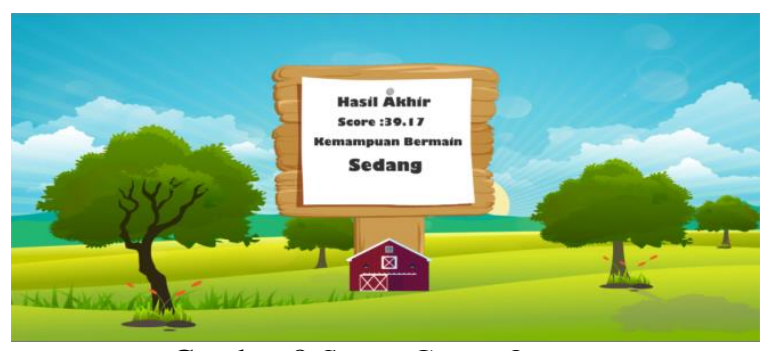

\section{Gambar 8 Scene Game Over}

Pada scene Game over menampilkan score dan kemampuan bermain pemain. Score dan kemampuan dihitung menggunakan fuzzy logic mamdani. Contoh penghitungannya seperti dibawah ini.

Contoh perhitungan dengan kecepatan 9 menit sedangkan ketepatan 70 .

- Kecepatan (9)

Kecepatan 9 menit berada pada area cepat sampai dengan sedang.

$\begin{array}{lll}\text { Cepat }:(10-9) / 5 & =0,2 \\ \text { Sedang }:(9-5) / 5 & =0,8\end{array}$

Lambat : 0

- $\quad$ Ketepatan (70)

Ketepatan 70 berada pada area sedang sampai dengan banyak.

Sedikit : 0

Sedang : $100-70 / 33,3=0,90$

Banyak : 70-66,6/33,3 =0,10

Rule base system secara lengkap disajikan dalam Tabel 1 Hasil rule base yang cocok adalah rule rule 2 , rule 3 , rule 5 dan 6 . Selanjutnya, nilai 
tiap variabel diambil minimumnya dari setiap rule base.

R2. IF kecepatan CEPAT AND ketepatan SEDANG THEN SEDANG

apredikat $_{1}=\operatorname{MIN}(0,2 ; 0,90)=0,2$

R3. IF kecepatan CEPAT AND ketepatan BANYAK THEN MAHIR

apredikat $_{2}=\operatorname{MIN}(0,2 ; 0,1)=0,1$

R5. IF kecepatan SEDANG AND ketepatan

SEDANG THEN SEDANG

apredikat $_{3}=$ MIN $(0,8 ; 0,90)=0,8$

R6. IF kecepatan SEDANG AND ketepatan

BANYAK THEN SEDANG

opredikat $_{4}=\operatorname{MIN}(0,8 ; 0,10)=0,1$

Komposisi aturan

Aturan pertama (R2)

$\mu \operatorname{sedang}(Z)=$

$\left\{\begin{array}{c}0 \\ \left(\frac{Z-30}{15}\right)=0,2 ; Z=(15 \times 0,2)+30=33 \\ \left(\frac{60-Z}{15}\right)=0,2 ; Z=60-(15 \times 0,2)=57\end{array}\right.$

Aturan kedua $(\mathbf{R 3})$

$\mu$ mahir $(\mathrm{Z})=$

$\left\{\begin{array}{c}\left(\frac{Z-60}{20}\right)=0,1 ; Z=(20 \times 0,1)+60=62 \\ \left(\frac{100-Z}{20}\right)=0,1 ; Z=100-(20 \times 0,1)=98\end{array}\right.$

Aturan ketiga (R5)

$\mu$ sedang $(Z)=$

$\left\{\begin{array}{c}0 \\ \left(\frac{Z-30}{15}\right)=0,8 ; Z=(15 \times 0,8)+30=42 \\ \left(\frac{60-Z}{15}\right)=0,8 ; Z=60-(15 \times 0,8)=48\end{array}\right.$

Aturan keempat (R6)

$\mu \operatorname{sedang}(\mathrm{Z})=$

$\left\{\begin{array}{c}\left(\frac{Z-30}{15}\right)=0,1 ; Z=(15 \times 0,1)+30=31,5 \\ \left(\frac{60-Z}{15}\right)=0,1 ; Z=60-(15 \times 0,1)=58,5\end{array}\right.$

Proses pengambilan keputusan fuzzy mamdani menggunakan perhitungan weight average:

$$
\begin{aligned}
Z^{*}= & \sum \frac{\mu(z) \cdot z}{\mu(z)} \\
Z^{*}= & ((0,8 \times 42)+(0,8 \times 48)+(0,2 \times 33)+(0,2 \times \\
& 57)+(0,1 \times 62)+(0,1 \times 98)+(0,1 \times \\
& 58,5)+(0,1 \times 31,5)) /(0,8 \times 2)+(0,1 \times 4)+ \\
& (0,2 \times 2)
\end{aligned}
$$

$=47,9 \approx 48$ (Sedang)

6. Distribution

Tahap ini aplikasi akan disimpan dalam suatu media penyimpanan. Tahap ini juga dapat disebut tahap evaluasi untuk pengembangan produk yang sudah jadi supaya menjadi lebih baik. Hasil evaluasi ini dapat digunakan sebagai masukan untuk tahap concept pada produk selanjutnya. (Rasel, 2014)

\section{Kesimpulan dan Saran}

\subsection{Kesimpulan}

Berdasarkan penelitian yang telah dilakukan pada game Oryza Farm Village maka dapat diambil kesimpulan sebagai berikut :

1. Perancangan simulasi pertumbuhan tanaman padi supaya dapat sesuai dengan kehidupan nyata adalah dengan merancang desain simulasi berbasis 3D dengan alur yang sama dengan cara menanam padi di dunia nyata.

2. Hama dibuat secara random, tergantung populasi jumlah tanaman padi kecil yang ditanam oleh pemain atau user. Semakin banyak tanaman padi kecil yang ditanam kemungkinan hama yang muncul juga semakin banyak. Hama di dalam simulasi akan memakan tanaman dan berdampak mati sampai berubah menjadi kering.

3. Berdasarkan kuesioner sebanyak 22 responden menyimpulkan pembelajaran menanam padi $84 \%$ sangat membantu dari aspek ilmu pengetahuan cara menanam dengan predikat memuaskan sedangkan $16 \%$ dalam kategori cukup membantu.

\subsection{Saran}

Penelitian ini masih dapat di kembangkan menjadi game yang lebih kompleks lagi dalam simulasi penanaman padi seperti jumlah hama yang ditambah, memperbaiki desain dan animasi konten (tanaman padi, toko, peralatan pertanian yang lebih modern) agar lebih menarik.

\section{Daftar Pustaka :}

Abdulrachman, Sarlan.,dkk., (2013): Petunjuk Teknis Lapang Pengelolaan Tanaman Terpadu (PTT) Padi Sawah Irigasi, Jakarta, Badan Penelitian dan Pengembangan Pertanian Kementerian Pertanian

Kurnia, Deni, (2012): Modul Membuat Game dengan Unity 3D Engine Tutorial step by step dari nol hingga mahir?, [Online]

Tersedia: www.academia.edu/11005999/Mudah_Mem buat_Game_dengan_Unity3D. [01 Maret 2016]

Kusumadewi, S., \& Purnomo, S., (2010): Aplikasi Logika Fuzzy untuk Pendukung Keputusan, Yogyakarta, Graha Ilmu

Novak, J., (2012): Game Development Essentials Third Edition, New York: Delmar.

Putri, N. A.,(2014): Game Scoring Non Player Character Menggunakan Agen Cerdas 
Berbasis Fuzzy Mamdani, Seminar Nasional Teknologi Informasi \& Komunikasi Terapan (SEMANTIK) 2014, pp. 142-149

Rasel., (2014): Multimedia System Development Life Cycle (MSDLC), [Online] Tersedia: http://bankofinfo.com/multimedia-systemdevelopment-life-cycle-msdlc/. Desember 2015].

Roedavan, R., (2016): Unity Tutorial Game Engine Edisi Revisi, Bandung, Informatika

Siregar, H., (1981): Budidaya Tanaman Padi di Indonesia, Bogor, Sastra Hudaya 